Proceedings of the 33rd Annual Meeting of the Brazilian Embryo Technology Society (SBTE); Ilha de Comandatuba, BA, Brazil, August 15th to 19th, 2019.

\title{
Pre-TAI protocol strategies to increase reproductive efficiency in beef and dairy cows
}

\author{
José Nélio de Sousa Sales ${ }^{1, *}$, Luiz Manoel Souza Simões ${ }^{1}$, Raphael Evangelista Orlandi ${ }^{1}$, \\ Eduardo Alves Lima', Ana Paula Castro Santos', Miguel Pizzolante Bottino', \\ Luiz Augusto Capellari Leite da Silva ${ }^{1}$, José Camisão de Souza ${ }^{2}$, Marcelo Maronna Dias ${ }^{3}$, \\ João Paulo Martinelli Massoneto ${ }^{4}$, Luiz Antônio Scandiuzzi Jr. ${ }^{4}$, Bruno Gonzalez Freitas 5 , \\ Bruna Martins Guerreiro ${ }^{5}$, Michele Ricieri Bastos ${ }^{5}$ \\ ${ }^{1}$ Department of Veterinary Medicine, UFLA, Lavras, MG, Brazil. \\ ${ }^{2}$ Department of Animal Science, UFLA, Lavras, MG, Brazil. \\ ${ }^{3}$ Genex, CRI Genética Brasil, São Paulo, SP, Brazil. \\ ${ }^{4}$ Agua Preta Farm, Cocalinho, MT, Brazil. \\ ${ }^{5}$ Ouro Fino Saúde Animal, Ribeirão Preto, SP, Brazil.
}

\begin{abstract}
Ovulation synchronization protocols are well established in beef and dairy cows. However, the protocol response rate is around $70-90 \%$. In beef cows, factors such as inadequate nutrition and calf presence negatively impact the response of progesterone (P4)/estradiol-based ovulation synchronization protocols by interfering with GnRH release and consequently reducing LH pulsatility and final follicular development. In dairy cows, protocols based on GnRH and prostaglandin (Ovsynch) are the most widely used in the world. However, the efficiency of Ovsynch is dependent on the presence of a large follicle at the time of administration of the first GnRH. In these ovulation synchronization protocols, pre-synchronization protocols (Prostaglandins, Double Ovsynch and P4synch) are usually attempted in an effort to increase responses. Thus, the objective of this review was to discuss pre-ovulation synchronization strategies (administration of injectable P4 or energetic/protein supplementation or presynchronization with intra-vaginal progesterone devices) aiming to increase the LH pulsatility in beef cows or induce the formation of a GnRH-responsive follicle at the beginning of the Ovsynch protocol in dairy cows.
\end{abstract}

Keywords: Conception rate; timed artificial insemination, LH, P4, pre-synchronization.

\section{Introduction}

Currently, the TAI protocols in beef and dairy cattle are well established, in which pregnancy rates between 30 and 65\% are observed (Baruselli et al., 2012; Sales et al., 2015; Wiltbank et al., 2015; Sales et al., 2016; Baruselli et al., 2017). However, the response to the TAI protocol (ovulation of largest follicle by inducer) based on estrogen and P4 is approximately $80 \%$ in Bos indicus lactating beef cows (Sales et al., 2012) and approximately $85 \%$ in dairy cows in GnRHbased protocols and PGF2 $\alpha$ (Souza et al., 2008; Silva et al., 2018).

In Bos indicus lactating beef cows, a long period of postpartum anestrous is observed characterized by normal initial follicular growth sustained by the release of FSH, reduction of the final growth of the dominant follicle and, consequently, absence of ovulation (Baruselli et al., 2004). These changes in the final follicular growth are due to the reduction of LH pulsatility after follicle deviation due to the calf presence and the reduced availability of forage (Jolly et al., 1995; Yavas and Walton, 2000). In cows in which the nutritional requirement is not met because of low feed availability, deficient GnRH secretion and consequently, LH release are observed (Jolly et al., 1995; Montiel and Ahuja, 2005). The reduction of GnRH secretion occurs due to the negative feedback in the hypothalamus promoted by the increase in the concentrations of neuropeptide Y, NEFA and betahydroxybutyrate produced by the mobilization of body fat (Hess et al., 2005). In addition to the nutritional effects, the calf presence blocks the secretion of GnRH by the hypothalamus through the action of released endogenous opioids (Malven et al., 1986; Williams et al., 1996). Under this condition, part of the cows do not respond to the TAI protocol due to a drastic reduction in LH pulsatility observed mainly in primiparous cows (Sales et al., 2016) and in undernourished cows with low body condition score (Grimard et al., 1995; Diskin et al., 2003).In Bos indicus lactating cows it is necessary to stimulate the hypothalamus to produce GnRH to increase LH pulsatility which would allow for the final growth of the dominant follicle and ovulation. The positive effects of ovulation synchronization protocols in anestrous cows are mainly due to the stimulation of exogenous P4 on the pulsatility of $\mathrm{GnRH}$ and $\mathrm{LH}$ (Rhodes et al., 2002), allowing the ovulation of a preovulatory follicle in the recent postpartum period (Baruselli et al., 2017). During the early postpartum period, progesterone reduces the expression of estradiol receptors in the hypothalamus by interfering with the hormone receptor-negative feedback in LH secretion (Ireland and Roche, 1982; Day, 2004). However, in underfed cows with body condition score $<2.5$ or primiparous, the final growth of the dominant follicle is lesser, resulting in small follicles at the time of TAI (Sales et al., 2016). Thus, in females that do not respond to the TAI protocol, the period of exposure to P4 during the ovulation synchronization protocol may not be sufficient to increase the LH pulsatility needed for ovulation to occur. Therefore, supplementation with P4 prior to the protocol is an alternative to improve the 
reproductive efficiency of beef cows submitted to TAI protocols (Simões et al., 2018). In addition to the effects of P4 in Bos indicus beef cows, energy/protein supplementation may increase the reproductive efficiency of beef cows submitted to the TAI protocol (Peres et al., 2016; Orlandi et al., 2018).

In dairy cows, the protocols based on GnRH and PGF2 $\alpha$ are predominant due to the ban on the use of esters of estradiol in some countries. The standard protocol used based on GnRH and PGF2 $\alpha$ is Ovsynch (Pursley et al., 1995). In spite of attending to the ovulation synchronization assumptions, there is low synchronization efficiency (64\%) in this protocol when administered on a random day of the estrous cycle (Vasconcelos et al., 1999). The best results to start the Ovsynch protocol is between the 5th and 12th day of the estrous cycle, as at this period is common to have a dominant follicle responsive to the GnRH treatment (Vasconcelos et al., 1999). Thus, pre-synchronization protocols are used to increase the proportion of cows with a responsive dominant follicle at the first GnRH of the ovsynch protocol (Moreira et al., 2001). Among the pre-synchronization protocols, Double-Ovsynch has presented a better synchronization result, with ovulation rates at the first $\mathrm{GnRH}$ of around $82 \%$ and pregnancy rates of $49.7 \%$ (Souza et al., 2008). However, some limitations (long protocol of 28 days and many animal handling) prevent extensive use of this protocol. In addition, to stimulating LH pulsatility, P4 (single intravaginal P4 devices) may be an alternative to induce the formation of large follicles that responds to the first GnRH of the Ovsynch protocol (Silva et al., 2018). Cows with P4 devices develop follicular persistence due to absence of pre-ovulatory peak of LH and maintenance of sub luteal concentrations of progesterone (Cerri et al., 2009). Persistent follicles are capable of ovulating after long periods (15 days) of progestogen blocking (Chebel et al., 2006). Thus, the persistent follicle can be used as a pre-synchronization method for the Ovsynch protocol due to the constant follicular development and ovulatory capacity. Thus, the objective of this review was to propose strategies that increase the response to ovulation synchronization protocols in beef and dairy cows using P4 or protein/energy supplementation pre-protocol of TAI, aiming to increase LH pulsatility or induce a GnRH-responsive follicle at the beginning of the ovulation synchronization protocol.

\section{Strategies to increase LH pulsatility prior to TAI protocols}

Postpartum anestrous in cows is caused in part by a reduction in LH pulsatility after follicular divergence (Yavas and Walton, 2000). This gonadotropin depletion is caused by the strong negative feedbacks from progesterone and estrogens in late pregnancy. The period of anovulatory anestrus varies between cows and milk production level. In dairy cows, the interval between calving and first ovulation ranges from 19 to 22 days (Darwash et al., 2010). However, in dairy cows on grazing systems, this interval may increase up to 43 days (McDougall et al., 1995). In Bos indicus beef cows raised in a continuous grazing system, longer postpartum anestrous periods are observed (>100 days ; Baruselli et al., 2004). Under this management system, between 5 and 15\% of the cows are cycling at the beginning of the breeding season (Sales et al., 2011; Baruselli et al., 2017). In this regards, strategies for stimulation of $\mathrm{GnRH}$-induced $\mathrm{LH}$ secretion during early postpartum to reduce anestrous period were attempted, such as P4 (Simões et al., 2018) and energetic/protein (Peres et al., 2016; Orlandi et al., 2018) supplementation.

\section{Progesterone}

Progesterone increases LH pulsatility by reducing the expression of estrogen receptors in the hypothalamus, decreasing negative feedback for $\mathrm{GnRH}$ production and release (Anderson and Day, 1998; Day, 2004). Thus, treatment with P4 in anestrous cows increased follicular fluid estradiol concentration due to increased LH pulsatility and its LH receptors on granulosa and theca cells in pre-ovulatory follicles (Inskeep et al., 1988; Rhodes et al., 2002). Some studies have shown that the use of P4 stimulates cyclicity in lactating dairy cows (Fike et al., 1997; Lucy et al., 2001). Recently, our research group conducted studies to evaluate the effect of injectable $\mathrm{P} 4$ (P4i) on the reproductive efficiency of lactating Bos indicus cows submitted to TAI. In the first study (Simões et al., 2018) the effect of previous exposure to injectable progesterone (P4i) in TAI protocols on follicular growth and pregnancy rate of Bos indicus lactating cows was evaluated. In this study, 420 lactating anestrous Nelore cows were used. Cows were divided into one of three experimental groups (Control, P4, and P4GnRH), 10 days before (D-10) the beginning of the $\mathrm{P} 4$ and estrogen-based ovulation synchronization protocol (Sales et al., 2015). In the control group, cows were only submitted to the protocol based on P4 and estrogen. In the P4i group, cows received $150 \mathrm{mg}$ of $\mathrm{P} 4 \mathrm{i}$ (Sincrogest Injectable ${ }^{\circledR}$, Ouro Fino, Brazil) intramuscularly on D-10 and were submitted to the same ovulation synchronization protocol as in the Control group. In the $\mathrm{P} 4 \mathrm{iGnRH}$ group, cows received the same treatments of the $\mathrm{P} 4$ group associated with the administration of $10 \mu \mathrm{g}$ of buserelin (Sincroforte ${ }^{\circledR}$, Ouro Fino, Brazil) on D0. In this study, the P4i treatment increased the follicular diameter at the beginning of the TAI protocol and on the day of removal of the P4 device. In addition, cows receiving pre-protocol P4 were 1.68 times more likely to become pregnant after TAI than the control group (Tab. 1). In Bos taurus beef cows (Simões, unpublished data), receiving P4i treatment previous to TAI protocol increased P/AI [Control 45.6\% (118/259) and P4i 54.8\% (142/259); P = 0.03]. In another study (Santos et al., 2018) using 988 lactating Nelore cows in adequate body condition score $(\sim 3.0)$, a P4 treatment preceding the ovulation synchronization protocol did not improve pregnancy rate [Control 64.7\% (322/498) and P4i 62.9\% (308/490); $\mathrm{P}=0.55]$ and cyclicity 30 days after TAI [Control 39.8\% (70/176) and $\mathrm{P} 4 \mathrm{i} 39.6 \%(72 / 182) \mathrm{P}=0.78]$. Thus, probably in cows 
with adequate body condition LH pulsatility in postpartum should allow growth and ovulation of a preovulatory follicle. This difference in fertility after P4 treatment is probably due to the body condition of the animals in the different studies. In the study by Simões et al. (2018), the cows were nutritionally impaired which resulted in low body condition scores. Nutritionally deficient cows have lower postpartum LH pulsatility due to the formation of metabolites (NEFA, Beta-hydroxybutyrate and acetate), endorphins and peptides (mainly neuropeptide $\mathrm{Y}$ ) known to produce negative feedback blocking hypothalamic GnRH (Hess, 2005). Thus, treatment with P4 prior to ovulation synchronization protocols may have increased $\mathrm{LH}$ secretion (Anderson and Day, 1998; Day, 2004), which resulted in higher pregnancy rates.

Based on the benefits reported here, we hypothesize that the prior use of P4 could replace eCG in TAI protocols (Simões, unpublished data). Research emphasizes the importance of treatment with eCG to increase both ovulation and pregnancy rates in TAI protocols (Baruselli et al., 2004; Sales et al., 2011; Sales et al., 2016). As shown previously, eCG has positive effects on recently calved anestrous cows (postpartum period less than 2 months) in animals with compromised body condition (Sales et al., 2011) and in cows with dominant follicle growth impairment due to high levels of progesterone at the end of the ovulation synchronization treatment (Baruselli et al., 2004). Despite the great benefits of eCG, the use of this gonadotrophin is banned in some countries and a resistance front has emerged because of the way it is extracted from mares. In addition, eCG has no activity pattern and its cost is extremely high. In the Simões study (unpublished data), 600 lactating Nelore multiparous cows were used and distributed in four experimental groups. In the control group $(n=150)$, cows were submitted to an ovulation synchronization protocol based on P4 and estrogen (D0 - 2mg estradiol benzoate $(\mathrm{EB})+\mathrm{P} 4$ device; $\mathrm{D} 8$ - withdrawal P4 device $+1 \mathrm{mg}$ estradiol cypionate (EC) + 500ug Cloprostenol; D10 - TAI). In the eCG group, cows were submitted to the same ovulation synchronization protocol of the Control group associated with the administration of 300 IU of eCG in D8. In the P4i group, the cows were submitted to the same TAI protocol of the control group associated with the administration of $150 \mathrm{mg}$ of injectable P4 (Sincrogest injectable $\left.{ }^{\circledR}\right) 10$ days before the initiation of the ovulation synchronization protocol. In the P4ieCG group, cows underwent the same TAI protocol from the Control group associated with the administration of $150 \mathrm{mg}$ of injectable P4 and 300UI of eCG in D8. The association of eCG with P4i prior to the protocol increased follicular diameter at day 10 of the TAI protocol. However, the use of $\mathrm{P} 4 \mathrm{i}$ without the administration of eCG resulted in a lower pregnancy rate. However, there was an additive gain in pregnancy rate with the association of eCG and P4i prior to the protocol, similar to that previously observed in Bos indicus cows (Simões et al., 2018). Thus, in Bos indicus cows, P4 treatment prior to the TAI protocol is not a viable alternative to replace eCG.

Table 1. Effects of exposure to injectable progesterone previous to TAI protocol on follicular growth, CL diameter and ovulation rate of suckled Nelore cows.

\begin{tabular}{lcccc}
\hline & Control & P4i & P4iGnRH & P \\
\hline Diameter (mm) & & & & \\
LF on Day 0 (mm) & $10.9 \pm 0.2^{\mathrm{b}}$ & $12.7 \pm 0.3^{\mathrm{a}}$ & $12.6 \pm 0.4^{\mathrm{a}}$ & 0.001 \\
LF on Day 8 (mm) & $9.7 \pm 0.2^{\mathrm{b}}$ & $10.4 \pm 0.2^{\mathrm{a}}$ & $9.9 \pm 0.2^{\mathrm{ab}}$ & 0.05 \\
LF on Day 10 (mm) & $12.6 \pm 0.3$ & $13.0 \pm 0.3$ & $12.6 \pm 0.3$ & 0.21 \\
CL on Day 24 (mm) & $19.7 \pm 0.4^{\mathrm{ab}}$ & $20.1 \pm 0.4^{\mathrm{a}}$ & $18.5 \pm 0.4^{\mathrm{b}}$ & 0.001 \\
Follicular growth rate (mm/day) & $1.4 \pm 0.1$ & $1.4 \pm 0.1$ & $1.3 \pm 0.1$ & 0.34 \\
Ovulation rate (\%) & 78.2 & 80.3 & 75.2 & 0.62 \\
& $(104 / 133)$ & $(110 / 137)$ & $(106 / 141)$ & \\
CL presence on Day 8 (\%) & 0.0 & 0.0 & 26.4 & 0.001 \\
P/AI & $(0 / 136)^{\mathrm{b}}$ & $(0 / 140)^{\mathrm{b}}$ & $(38 / 144)^{\mathrm{a}}$ & 0.01 \\
\hline
\end{tabular}

Abbreviations: LF - largest follicle; CL - Corpus Luteum; P/AI - pregnancy per timed-AI. Control group - cows were only submitted to the conventional protocol based on P4 and estrogen P4i group - cows received 150mg of progesterone injectable intramuscularly 10 days before initiation of the ovulation synchronization protocol (D-10). $\mathrm{P} 4 \mathrm{iGnRH}$ group - cows received the same treatments of the P4 group associated with the administration of $10 \mu \mathrm{g}$ of buserelin on D0. Different letters $(\mathrm{a} \neq \mathrm{b})$ in the same line differ $(\mathrm{P}<0.05$; Simões et al., 2018).

\section{Energetic and protein supplementation}

Under feed restriction cows mobilize body energy reserves, resulting in increases in the concentration of neuropeptide Y (McShane et al., 1993) and NEFA from mobilization of body energy reserves (DiCostanzo et al., 1999) which, in turn, block the secretion of GnRH and, consequently, the release of $\mathrm{LH}$ (Schillo, 1992). In addition, cows in negative energetic balance have high concentrations of $\beta$-hydroxybutyrate and low glucose concentrations that reduce $\mathrm{GnRH}$ secretion by the hypothalamus (Mulliniks et al., 2013). Therefore, adequate nutrition during the pre-partum period and the amount of dry matter available in postpartum are key elements for the return to cyclicity in dairy and beef cows (Crowe et al., 2014). Studies have shown that cows with adequate body condition pre and postpartum have greater fertility after calving (Sa Filho et al., 2009; Ayres et al., 2014) and that energy and/or protein supplementation increases the conception 
rate (Pescara et al., 2010). In a recent study by our research group (Orlandi et al., 2018), the effect of energy and protein supplementation on follicular growth and pregnancy rate of Bos indicus lactating cows was evaluated. In this study, 342 Bos indicus (Nelore) cows in anestrus were distributed in Control (nonsupplemented cows) and Supplement (cows received $2.5 \mathrm{~kg} /$ day of an energy/protein supplement with $26.5 \%$ $\mathrm{CP}$ and $76.5 \%$ NDT for 26 days) groups. Supplementation was initiated 12 days prior to a standard P4 and estradiol based-TAI protocol and maintained for
14 days. After the first TAI, the non-pregnant cows were resynchronized and 10 days after the second TAI were exposed to Nelore clean-up bulls until the end of the breeding season, which lasted for 110 days. The diameter of the largest follicle at D0, D8, D10, CL diameter at D14 and ovulation rate were higher $(\mathrm{P}<0.05)$ in the Supplement group. In addition, there were no differences $(\mathrm{P}>0.05)$ between the treatments for $\mathrm{P} / \mathrm{AI}$ at $1^{\text {st }}$ and $2^{\text {nd }}$ TAI or after the clean-up bull. However, the pregnancy rate at the end of the breeding season was greater in the Supplement group $(\mathrm{P}=0.02$; Fig. 1$)$.

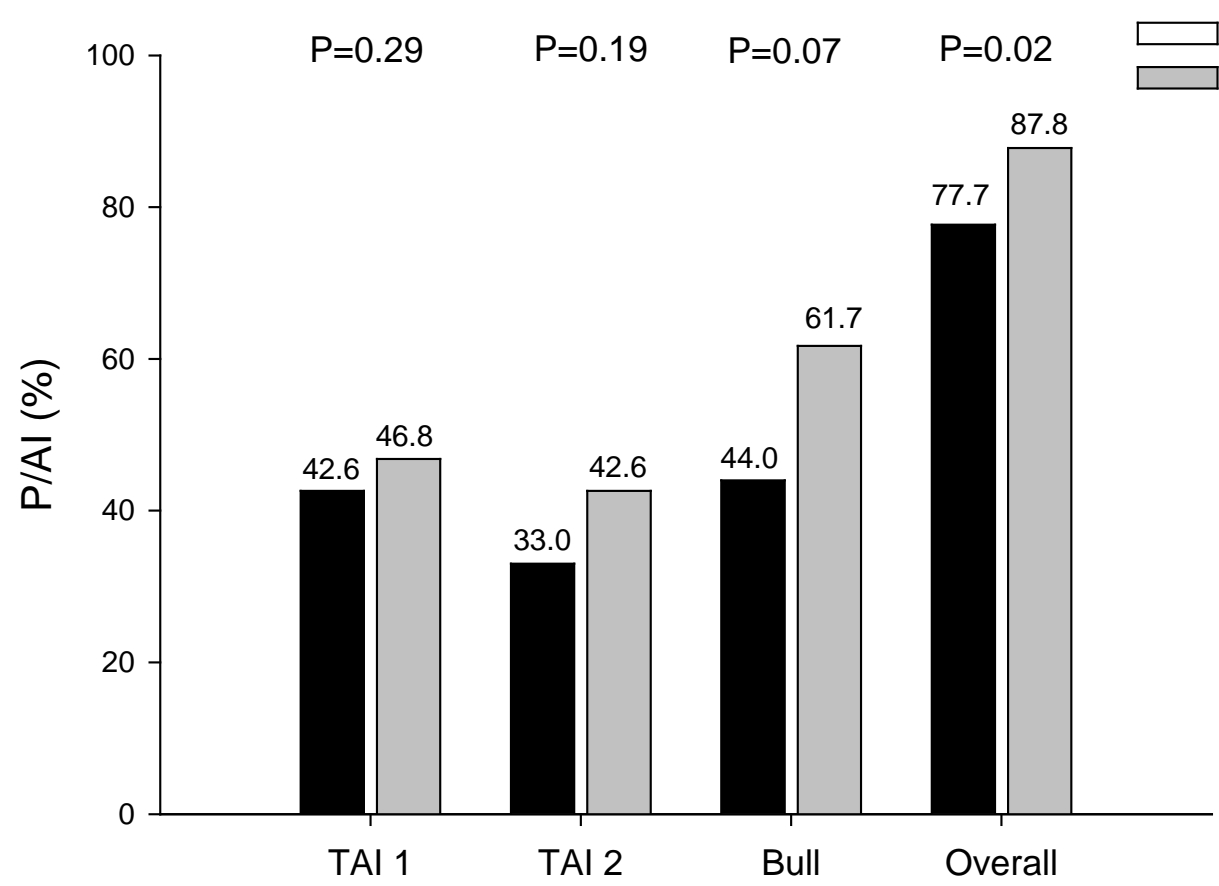

Figure 1. P/AI during a 110-day breeding season of lactating Nelore cows supplemented with energy and protein diet at the end of the dry period (Orlandi et al., 2018).

In another supplementation study in beef cows (Peres et al., 2016), the effect of corn-based supplementation was evaluated for 41 days. The supplementation started on the first day of insertion of the P4 device (D0) in the TAI protocol and remained until pregnancy check (D41). In this study two experiments were carried out to evaluate the hormonal profile and the fertility of Nelore females. In the study, the three-way TAI protocol with 11-day duration was used. In experiment 1,681 primiparous cows averaging 2.84 in BCS were used to evaluate the concentrations of IGF-1, leptin and GH and in experiment 2, 2395 Nelore females (648 heifers, 635 primiparous and 1112 multiparous) were submitted to the TAI protocol to evaluate fertility. In both experiments cows were distributed into two groups, Control (not supplemented) and Supplemented $(1.0 \mathrm{~kg} / \mathrm{cow} /$ day of corn from D0 to D11 and 2.2kg/cow/day from D11 to D41). Both groups grazed on pastures with ad libitum access to water and mineral and TAI protocols started 35 days post calving. In experiment 1 , the higher concentration of IGF-1 at TAI (138.4 vs $130.8 \mathrm{ng} / \mathrm{mL}$ ) and lower concentration on the day of the pregnancy diagnosis (135.5 vs
$141.5 \mathrm{ng} / \mathrm{mL}$ ) were observed in the supplemented cows. In this study, cows with higher concentrations of IGF-1 at the time of TAI and leptin / GH at the beginning of the protocol had higher pregnancy rates, demonstrating that supplementation during the protocol may increase the pregnancy rate due to an increase in the concentration of IGF-1. In experiment 2, although cornbased supplementation did not interfere with the results of the first TAI (Control - 50.9\% and Supplemented $52.4 \%$ ), there was a trend of higher pregnancy rate in the second TAI in supplemented cows $(44.3 \%$ vs. $38.5 \%$ ). In addition, primiparous cows had higher pregnancy rate at the end of the breeding season $(77.8 \%$ vs. $65.7 \%$ ), showing cumulative/late effects similar to those observed in Orlandi et al. (2018). However, in multiparous, the final pregnancy rate was lower in the supplemented group (87.0\% vs. $92.0 \%)$. These results make it difficult to understand the effects of energy supplementation on beef cows during and after the TAI protocol. Thus, the positive effects of nutrition may occur due to changes in hormone concentrations (insulin and IGF-I) and metabolites (glucose, cholesterol and beta-hydroxybutyrate) related to reproductive efficiency 
(Beam and Butler, 1998; Ospina et al., 2010; Mulliniks et al., 2013; Samadi et al., 2013). Thus, short duration( $<30$ days) energy and protein supplementation 12 days before TAI sufficient to animal maintenance increased fertility lactating beef cows in the post postpartum period, being an interesting alternative.

\section{Strategies to increase response to the first GnRH of the Ovsynch protocol}

Ovsynch is the standard GnRH/PGF2 $\alpha$-based protocol (Pursley et al., 1995) where a first $\mathrm{GnRH}$ is given on a random day of the estrous cycle (D0). Seven days later, PGF2 $\alpha$ (D7) is given and 48 hours later, a second GnRH. Cows are inseminated 16 hours after the second GnRH. Although it meets the three premises of ovulation synchronization, this protocol presents low efficiency (64\%) if administered in animals on a random day of the estrous cycle (Vasconcelos et al., 1999). In this study, ovulation rate was higher in cows that received the first $\mathrm{GnRH}$ of the Ovsynch protocol between days 5 - 9 and 17 - 21 days of the estrous cycle. In addition, there was a higher ovulation rate to the second GnRH of the Ovsynch protocol when the animals responded to the first GnRH (Vasconcelos et al., 1999). However, cows that did not respond to the first $\mathrm{GnRH}$ had a longer period of dominance of the ovulatory follicle (follicular persistence), compromising oocyte quality and early embryo development (Cerri et al., 2009). Such changes in follicular dynamics resulted in a lower pregnancy rate (Chebel et al., 2006). Thus, pre-synchronization protocols have been used to increase the response to the first GnRH of the Ovsynch protocol, (Moreira et al., 2001; Souza et al., 2008).

The first pre-synchronization protocol used two PGF2 $\alpha$ with a 14-day interval, followed by Ovsynch 12 days after the second PGF2 $\alpha$ (termed PresynchOvsynch; Moreira et al., 2001). Pre-synchronization in this study increased the conception rate (37\% vs 49\%) in heifers by 12 percentage points and other authors observed an increase of 18 percentage points in cyclic lactating cows (25\% vs 43\%; El-Zarkouny et al., 2001). In another study, using a similar protocol (twelve day intervals between PGF2 $\alpha$ injections) conception rates at 42 days of gestation was $49.6 \%$ for the cows in the Presynch group and $37.3 \%$ for cows in the Ovsynch group (Navanukraw et al., 2004). Thus, such favorable results are attributed to a larger number of animals in the optimal phase of the estrous cycle receiving the Ovsynch protocol. However, only cyclic cows can benefit from the program with two PGF2 $\alpha$ since the response depends on the presence of responsive corpus luteum (Chebel et al., 2006). Another limitation of the effectiveness of the Presynch-Ovsynch protocol would be the lack of precision in follicular synchronization and luteal stages, due to estrous variability and ovulation after PGF2 $\alpha$ treatments (Ayres et al., 2013).

Among the pre-synchronization protocols, Double Ovsynch (Ovsynch protocol is performed as a pre-synchronization tool) has achieved better synchronization results (Souza et al., 2008). DoubleOvsynch comprises two Ovsynch protocols seven-days apart, with TAI after the last GnRH of the second protocol. Double-Ovsynch increases the ovarian response to hormone treatment and $\mathrm{P} 4$ concentrations during the Ovsynch of the TAI (Souza et al., 2008). In this study, 28\% more cows with high progesterone ( $>3 \mathrm{ng} / \mathrm{mL}$ ) were observed at the time of PGF2 $\alpha$ in the Double-Ovsynch group (78.1\% vs 52.3\%) when compared to the group treated with two PGF2 $\alpha$. In addition, there was a high ovulation rate at the first GnRH (82\%) and a satisfactory pregnancy rate (49.7\%). In another study (Herlihy et al., 2012), Double-Ovsynch reduced the proportions of primiparous and multiparous cows with low circulating P4 concentrations compared to Presynch-Ovsynch treated cows (3.3 vs $19.7 \%$ in primiparous and 8.8 vs $31.9 \%$ in multiparous). Cows with low concentrations of P4 at the time of PGF2 $\alpha$ administration are more likely to have premature luteolysis, with consequent peak LH and ovulation prior to administration of the second Ovsynch GnRH (Vasconcelos et al., 1999). In both studies, the DoubleOvsynch protocol increased Ovsynch fertility compared to Presynch-Ovsynch. The ovulatory response to the first Ovsynch $\mathrm{GnRH}$ increases the circulating concentrations of progesterone and allows the development of the dominant follicle less variable and closer to the ideal size at the time of the second GnRH (Bello et al., 2006; Giordano et al., 2012). Increased circulating concentrations of P4 during follicular development may decrease LH pulsatility, possibly increase dominant follicle competence, oocyte and uterine environment qualities (Mihm et al., 1994; Revah and Butler, 1996). Other studies also related ovulation to the first Ovsynch GnRH and the presence of CL at the time of PGF2 $\alpha$ with higher pregnancy rates at 30 and 60 days post artificial insemination (Vasconcelos et al., 1999; Chebel et al., 2006). However, such a protocol is too long (28 days) and difficult to implement on farm. Thus, there is still the need for the development of more practical and shorter presynchronization protocols.

Recently our research group developed a presynchronization protocol using a P4 sustained-release vaginal device (Silva et al., 2018) to induce a persistent dominant follicle to increase the response to the first $\mathrm{GnRH}$ of the Ovsynch protocol. In the experiment, 440 dairy cows (345 Holstein-Zebu crossbreds and 95 Holsteins) were randomly assigned to Double Ovsynch (Double-Ov; Souza et al., 2008) and P4synch. The P4synch protocol consisted of insertion of an intravaginal P4 device 10 days prior to the initiation of the Ovsynch protocol (D-10) and withdrawing the device on the day of PGF2 $\alpha$ administration of the Ovsynch (D7) protocol. All cows were inseminated 16 hours after the second dose of GnRH from the Ovsynch protocol. No differences were observed between the groups for the pre-synchronization rate variables [presence of follicles with more than $12 \mathrm{~mm}$ in the $\mathrm{D} 0 ; \mathrm{P}=0.66$ ), follicular diameter at the $1^{\text {st }} \mathrm{GnRH}(\mathrm{P}=0.28)$, ovulation rate at $1^{\text {st }}$ GnRH $(P=0.50)$, synchronization rate $(P=0.84)$, follicular diameter at the $2^{\text {nd }} \mathrm{GnRH}(\mathrm{P}=0.48)$, ovulation rate in the $2^{\text {nd }} \mathrm{GnRH}(\mathrm{P}=0.48)$ and the diameter of the CL in D24 $(\mathrm{P}=0.19)$ ]. However, the 
presence of CL on D0 was higher $(P=0.03)$ in the Double Ovsynch group (Tab. 2). In addition, there was no difference in pregnancy rates at $30(\mathrm{P}=0.85)$, at 60 days of gestation $(\mathrm{P}=0.41)$ and in gestational losses at 30 and 60 days of gestation $(\mathrm{P}=0.13$; Fig. 2$)$. There was no difference in the percentage of cows with P4 $<1 \mathrm{ng} / \mathrm{mL}$ at D0 [Double-Ov 13.6\% (3/22) and P4synch $5.0 \%$ (1/20); $\mathrm{P}=0.37$ ], for percentage of cows with $\mathrm{P} 4$ $>1 \mathrm{ng} / \mathrm{mL}$ in D7 (Double-Ov 77.3\% and P4synch 95.0\%; $\mathrm{P}=0.14$ ) and for P4 concentration in D24 (Double-Ov
$4.7 \pm 0.6$ and P4synch $5.9 \pm 0.9 \mathrm{ng} / \mathrm{mL}, \mathrm{P}=0.84)$. The P4synch protocol has the same reproductive efficiency as the Double Ovsynch protocol in lactating dairy cows. In another study by our research group (Lima, unpublished data), we compared the P4synch protocol with the protocol based on estrogen and P4 (Ferreira et al., 2013). In this study, similar results were reported between the P4synch and the P4-estradiol-based protocols (Tab. 3). Thus, P4synch may be an efficient alternative for ovulation synchronization in dairy cows.

Table 2. Effect of presynchronization (Double Ovsynch and P4synch) on the follicular dynamics of lactating crossbred dairy cows submitted to the Ovsynch protocol.

\begin{tabular}{lccc}
\hline & Double-Ov & P4synch & P \\
\hline Rates (\%) & & & 0.66 \\
Presynchronization & $94.2(49 / 52)$ & $92.0(46 / 50)$ & 0.03 \\
CL on Day 0 & $57.7(30 / 52)$ & $36.0(18 / 50)$ & 0.50 \\
Ovulation to 1 ${ }^{\text {st }}$ GnRH & $86.3(44 / 51)$ & $81.2(39 / 48)$ & 0.20 \\
Follicular persistence & $5.9(03 / 52)$ & $14.3(07 / 49)$ & 0.84 \\
Synchronization of Day 9 & $84.6(44 / 52)$ & $86.0(43 / 50)$ & 0.48 \\
Ovulation to 2 ${ }^{\text {nd }}$ GnRH & $90.9(40 / 44)$ & $86.0(37 / 43)$ & \\
Diameters (mm) & & & 0.28 \\
LF on Day 0 & $17.2 \pm 07$ & $18.6 \pm 0.8$ & 0.48 \\
LF on Day 9 & $17.6 \pm 0.5$ & $17.9 \pm 0.4$ & 0.19 \\
CL on Day 24 & $27.9 \pm 0.7$ & $29.4 \pm 0.8$ &
\end{tabular}

Abbreviations: LF, largest follicle; CL, Corpus Luteum. a) Presynchronization: presence of follicle $>12 \mathrm{~mm}$ on D0. b) Follicular persistence: presence of follicle $>12 \mathrm{~mm}$ on D0, absence of CL on D7 and follicle $>20 \mathrm{~mm}$ on D9. c) Synchronization: presence of a follicle $>12 \mathrm{~mm}$. The P4synch protocol consisted of insertion of an intravaginal P4 device 10 days prior to the initiation of the Ovsynch protocol (D-10) and withdrawing the device on the day of PGF2 $\alpha$ administration of the Ovsynch (D7) protocol (Silva et al., 2018).

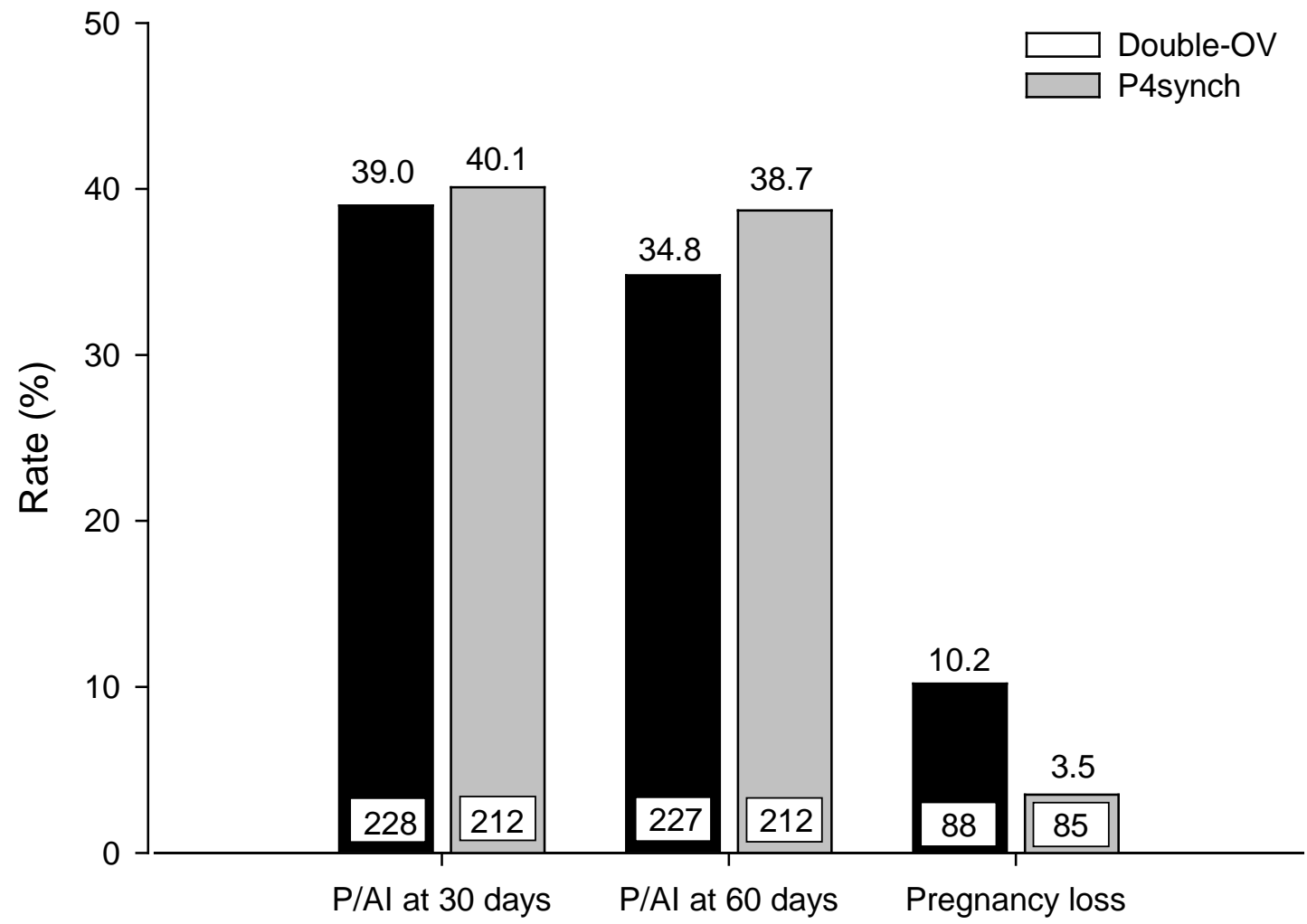

Figure 2. Effect of the presynchronization protocol (Double-Ov and P4synch) on the P/AI at 30 and 60 days and pregnancy loss ( $\mathrm{P}>0.05$ ) in lactating crossbred dairy cows (Silva et al., 2018). 
Sales et al. Pre-TAI protocol strategies in beef and dairy cows.

Table 3. Effect of protocols (P4E2 and P4synch) on the follicular dynamics and fertility of lactating dairy cows.

\begin{tabular}{|c|c|c|c|}
\hline & P4E2 & P4synch & $\mathrm{P}$ \\
\hline \multicolumn{4}{|l|}{ Rates (\%) } \\
\hline Presynchronization & $73.9(34 / 46)$ & $97.8(45 / 46)$ & 0.01 \\
\hline CL on Day 0 & $80.4(37 / 46)$ & $37.0(17 / 46)$ & 0.001 \\
\hline Ovulation to $1^{\text {st }} \mathrm{GnRH}$ & $65.2(30 / 46)$ & $65.2(30 / 46)$ & 0.99 \\
\hline Follicular persistence & $8.7(4 / 46)$ & $15.2(7 / 46)$ & 0.34 \\
\hline Synchronization on induction & $76.1(35 / 46)$ & $80.4(37 / 46)$ & 0.61 \\
\hline \multicolumn{4}{|l|}{ Diameters (mm) } \\
\hline LF on Day 0 & $15.0 \pm 0.8$ & $21.0 \pm 0.8$ & 0.001 \\
\hline LF on induction & $13.9 \pm 0.7$ & $17.6 \pm 0.6$ & 0.001 \\
\hline LF on TAI & $15.2 \pm 0.7$ & $17.2 \pm 0.8$ & 0.05 \\
\hline $\mathrm{P} / \mathrm{AI}$ & $37.4(67 / 179)$ & $42.4(72 / 170)$ & 0.35 \\
\hline
\end{tabular}

Abbreviations: LF, largest follicle; CL, Corpus Luteum. a) Presynchronization: presence of follicle $>12 \mathrm{~mm}$ on D0. b) Follicular persistence: presence of follicle $>12 \mathrm{~mm}$ on D0, absence of CL on D7 and follicle $>20 \mathrm{~mm}$ on D9. c) Synchronization on induction: presence of a follicle $>12 \mathrm{~mm}$. The P4synch protocol consisted of insertion of an intravaginal P4 device 10 days prior to the initiation of the Ovsynch protocol (D-10) and withdrawing the device on the day of PGF2 $\alpha$ administration of the Ovsynch (D7) protocol (Lima et al., unpublished).

\section{Conclusion}

The TAI protocols in beef and dairy cows are well established, but the response to protocols ranges from 70 to $90 \%$. Currently, there are strategies to increase protocol response in cows with LH release impairment. The P4i strategy brought significant increase in fertility in Bos indicus and Bos taurus beef cows. Another strategy that has improved TAI results in Bos indicus beef cows is energy/protein supplementation before and during the protocol. In addition, the use of intravaginal $\mathrm{P} 4$ device is an efficient alternative of pre-synchronization to the Ovsynch protocol in dairy cows.

Despite these results, more studies are necessary to confirm these findings, especially in energy/protein supplementation.

\section{Author contributions}

JNSS: Conceptualization, Funding acquisition, Supervision, Project administration, Writing - original draft, Writing - review \& editing, Formal analysis, Methodology, Investigation; LMSS, REO, EAL, APCS, MPB, LACLS, , BGF, BMG, MRB: Investigation; JPMM, LASJ, MMD: Investigation, Resources; JCS: Conceptualization, Writing - original draft, Methodology.

\section{Conflict of interest}

The authors claim no conflict of interest.

Acknowledgments and Funding disclosure statement

The authors are grateful to Agua Preta Farm and other farms of South and Southeast of Brazil for allowing the use of their animals and facilities for this study. This research was supported by Ouro Fino Agronegocio (pharmacological products), CNPq (Processo: 456398/2014-7 and scholarship), FAPEMIG (scholarship) and CAPES (scholarship).

\section{References}

Anderson LH, Day ML. 1998. Current Concepts on the Control of Puberty in Cattle. J Anim Sci, 76:1-15.

Ayres H, Ferreira RM, Cunha AP, Araujo RR, Wiltbank MC. 2013. Double-Ovsynch in highproducing dairy cows: effects on progesterone concentrations and ovulation to GnRH treatments. Theriogenology, 79:159-164.

Ayres H, Ferreira RM, Torres-Junior JR, Demetrio CG, Sa Filho MF, Gimenes LU, Penteado L, D'Occhio MJ, Baruselli PS. 2014. Inferences of body energy reserves on conception rate of suckled Zebu beef cows subjected to timed artificial insemination followed by natural mating. Theriogenology, 82:529-536.

Baruselli PS, Reis EL, Marques MO, Nasser LF, Bo GA. 2004. The use of hormonal treatments to improve reproductive performance of anestrous beef cattle in tropical climates. Anim Reprod Sci, 82-83:479-486.

Baruselli P, Sales JN, Sala R, Viera LM, Sá Filho M. 2012. History, evolution and perspectives of timed artificial insemination programs in Brazil. Anim Reprod, 9:139-152.

Baruselli P, Ferreira R, Colli M, Elliff F, Sá Filho M, Vieira L, Freitas B. 2017. Timed artificial insemination: Current challenges and recent advances in reproductive efficiency in beef and dairy herds in Brazil. Anim Reprod, 14:558-571.

Beam SW, Butler WR. 1998. Energy balance, metabolic hormones, and early postpartum follicular development in dairy cows fed prilled lipid. J Dairy Sci, 81:121-131.

Bello NM, Steibel JP, Pursley JR. 2006. Optimizing ovulation to first GnRH improved outcomes to each hormonal injection of ovsynch in lactating dairy cows. $J$ Dairy Sci, 89:3413-3424.

Cerri RL, Rutigliano HM, Bruno RG, Santos JE. 2009. Progesterone concentration, follicular development and induction of cyclicity in dairy cows receiving intravaginal progesterone inserts. Anim Reprod Sci, 110:56-70.

Chebel RC, Santos JE, Cerri RL, Rutigliano HM, Bruno RG. 2006. Reproduction in dairy cows 
following progesterone insert presynchronization and resynchronization protocols. J Dairy Sci, 89:4205-4219. Crowe MA, Diskin MG, Williams EJ. 2014. Parturition to resumption of ovarian cyclicity: comparative aspects of beef and dairy cows. Animal, 1:40-53.

Darwash AO, Lamming GE, Wooliams JA. 2010. The phenotypic association between the interval to postpartum ovulation and traditional measures of fertility in dairy cattle. Anim Sci, 65:9-16.

Day ML. 2004. Hormonal induction of estrous cycles in anestrous Bos taurus beef cows. Anim Reprod Sci, 8283:487-494.

DiCostanzo A, Williams JE, Keisler DH. 1999. Effects of short- or long-term infusions of acetate or propionate on luteinizing hormone, insulin, and metabolite concentrations in beef heifers. J Anim Sci, 77:3050-3056.

Diskin MG, Mackey DR, Roche JF, Sreenan JM. 2003. Effects of nutrition and metabolic status on circulating hormones and ovarian follicle development in cattle. Anim Reprod Sci, 78:345-370.

El-Zarkouny SZ, Cartmill JA, Richardson AM, Medina-Britos MA. 2001. Presynchronization of estrous cycles in dairy cows before ovsynch + CIDR and resynchronization of repeat estrus using the CIDR. Kansas Agricultural Experiment Station Research Reports, 0:52-54.

Ferreira RM, Ayres H, Sales JN, Souza AH, Rodrigues CA, Baruselli PS. 2013. Effect of different doses of equine chorionic gonadotropin on follicular and luteal dynamics and P/AI of high-producing Holstein cows. Anim Reprod Sci, 140:26-33.

Fike KE, Day ML, Inskeep EK, Kinder JE, Lewis PE, Short RE, Hafs HD. 1997. Estrus and luteal function in suckled beef cows that were anestrous when treated with an intravaginal device containing progesterone with or without a subsequent injection of estradiol benzoate. J Anim Sci, 75:2009-2015.

Giordano JO, Wiltbank MC, Guenther JN, Pawlisch R, Bas S, Cunha AP, Fricke PM. 2012. Increased fertility in lactating dairy cows resynchronized with Double-Ovsynch compared with Ovsynch initiated $32 \mathrm{~d}$ after timed artificial insemination. J Dairy Sci, 95:639653.

Grimard B, Humblot P, Ponter AA, Mialot JP, Sauvant D, Thibier M. 1995. Influence of postpartum energy restriction on energy status, plasma $\mathrm{LH}$ and oestradiol secretion and follicular development in suckled beef cows. J Reprod Fertil, 104:173-179.

Herlihy MM, Giordano JO, Souza AH, Ayres H, Ferreira RM, Keskin A, Nascimento AB, Guenther JN, Gaska JM, Kacuba SJ, Crowe MA, Butler ST, Wiltbank MC. 2012. Presynchronization with DoubleOvsynch improves fertility at first postpartum artificial insemination in lactating dairy cows. $J$ Dairy Sci, 95:7003-7014.

Hess B, Lake SL, Scholljegerdes EJ, Weston TR, Nayigihugu V, Molle JDC, Moss GE. 2005. Nutritional controls of beef cow reproduction. J Anim Sci, 83:90-106.

Inskeep EK, Braden TD, Lewis PE, Garcia-Winder
M, Niswender GD. 1988. Receptors for luteinizing hormone and follicle-stimulating hormone in largest follicles of postpartum beef cows. Biol Reprod, 38:587591.

Ireland JJ, Roche JF. 1982. Development of antral follicles in cattle after prostaglandin-induced luteolysis: changes in serum hormones, steroids in follicular fluid, and gonadotropin receptors. Endocrinology, 111:20772086.

Jolly PD, McDougall S, Fitzpatrick LA, Macmillan KL, Entwistle KW. 1995. Physiological effects of undernutrition on postpartum anoestrus in cows. $J$ Reprod Fertil Suppl, 49:477-492.

Lucy MC, Billings HJ, Butler WR, Ehnis LR, Fields MJ, Kesler DJ, Kinder JE, Mattos RC, Short RE, Thatcher WW, Wettemann RP, Yelich JV, Hafs HD. 2001. Efficacy of an intravaginal progesterone insert and an injection of PGF2 $\alpha$ for synchronizing estrus and shortening the interval to pregnancy in postpartum beef cows, peripubertal beef heifers, and dairy heifers. $J$ Anim Sci, 79:982-995.

Malven PV, Parfet JR, Gregg DW, Allrich RD, Moss GE. 1986. Relationships among concentrations of four opioid neuropeptides and luteinizing hormone-releasing hormone in neural tissues of beef cows following early weaning. J Anim Sci, 62:723-733.

McDougall S, Burke CR, MacMillan KL, Williamson NB. 1995. Patterns of follicular development during periods of anovulation in pasturefed dairy cows after calving. Res Vet Sci, 58:212-216.

McShane TM, Petersen SL, McCrone S, Keisler DH. 1993. Influence of food restriction on neuropeptide-Y, proopiomelanocortin, and luteinizing hormone-releasing hormone gene expression in sheep hypothalami. Biol Reprod, 49:831-839.

Mihm M, Baguisi A, Boland MP, Roche JF. 1994. Association between the duration of dominance of the ovulatory follicle and pregnancy rate in beef heifers. $J$ Reprod Fertil, 102:123-130.

Montiel F, Ahuja C. 2005. Body condition and suckling as factors influencing the duration of postpartum anestrus in cattle: a review. Anim Reprod Sci, 85:1-26.

Moreira F, Orlandi C, Risco CA, Mattos R, Lopes F, Thatcher WW. 2001. Effects of presynchronization and bovine somatotropin on pregnancy rates to a timed artificial insemination protocol in lactating dairy cows. $J$ Dairy Sci, 84:1646-1659.

Mulliniks JT, Kemp ME, Endecott RL, Cox SH, Roberts AJ, Waterman RC, Geary TW, Scholljegerdes EJ, Petersen MK. 2013. Does betahydroxybutyrate concentration influence conception date in young postpartum range beef cows? J Anim Sci, 91:2902-2909.

Navanukraw C, Redmer DA, Reynolds LP, Kirsch JD, Grazul-Bilska AT, Fricke PM. 2004. A modified presynchronization protocol improves fertility to timed artificial insemination in lactating dairy cows. J Dairy Sci, 87:1551-1557.

Orlandi RE, Simões LMS, Bottino MP, Santos APC, Lima EA, Massoneto JPM, Scandiuzzi LA, Jr., Pádua PHBM, Sales JNS. 2018. Energy and protein 
supplementation on follicular growth and pregnancy rate of Bos indicus lactating cows submitted to FTAI in a breeding season of 110 days. Anim Reprod, 15:329. (Abstract).

Ospina PA, Nydam DV, Stokol T, Overton TR. 2010. Associations of elevated nonesterified fatty acids and beta-hydroxybutyrate concentrations with early lactation reproductive performance and milk production in transition dairy cattle in the northeastern United States. J Dairy Sci, 93:1596-1603.

Peres RFG, Carvalho R, Graff H, Furlan Junior JH, Rodrigues ADP, Franco GA, Keisler DH, Smith MF, Pohler KG, Vasconcelos JLM. 2016. Corn supplementation during 41 days after the begginning of TAI protocol and its effects on metabolic hormones and reproductive performance of Nelore females. Anim Reprod, 13:382. (Abstract).

Pescara JB, Sá Filho OG, Losi TC, Cooke RF, Vasconcelos JLM. 2010. Serum progesterone concentration and conception rate of beef cows supplemented with ground corn after a fixed-time artificial insemination protocol. Arq Bras Med Vet e Zootec, 62:130-135.

Pursley JR, Mee MO, Wiltbank MC. 1995. Synchronization of ovulation in dairy cows using PGF2alpha and GnRH. Theriogenology, 44:915-923.

Revah I, Butler WR. 1996. Prolonged dominance of follicles and reduced viability of bovine oocytes. $J$ Reprod Fertil, 106:39-47.

Rhodes FM, Burke CR, Clark BA, Day ML, Macmillan KL. 2002. Effect of treatment with progesterone and oestradiol benzoate on ovarian follicular turnover in postpartum anoestrous cows and cows which have resumed oestrous cycles. Anim Reprod Sci, 69:139-150.

Sa Filho OG, Meneghetti M, Peres RF, Lamb GC, Vasconcelos JL. 2009. Fixed-time artificial insemination with estradiol and progesterone for Bos indicus cows II: strategies and factors affecting fertility. Theriogenology, 72:210-218.

Sales JNS, Crepaldi GA, Girotto RW, Souza AH, Baruselli PS. 2011. Fixed-time AI protocols replacing eCG with a single dose of FSH were less effective in stimulating follicular growth, ovulation, and fertility in suckled-anestrus Nelore beef cows. Anim Reprod Sci, 124:12-18

Sales JNS, Carvalho JB, Crepaldi GA, Cipriano RS, Jacomini JO, Maio JR, Souza JC, Nogueira GP, Baruselli PS. 2012. Effects of two estradiol esters (benzoate and cypionate) on the induction of synchronized ovulations in Bos indicus cows submitted to a timed artificial insemination protocol. Theriogenology, 78:510-516.

Sales JNS, Carvalho JB, Crepaldi GA, Soares JG, Girotto RW, Maio JR, Souza JC, Baruselli PS. 2015. Effect of circulating progesterone concentration during synchronization for fixed-time artificial insemination on ovulation and fertility in Bos indicus (Nelore) beef cows. Theriogenology, 83:1093-1100.

Sales JNS, Bottino MP, Silva LA, Girotto RW, Massoneto JP, Souza JC, Baruselli PS. 2016. Effects of eCG are more pronounced in primiparous than multiparous Bos indicus cows submitted to a timed artificial insemination protocol. Theriogenology, 86:2290-2295.

Samadi F, Phillips NJ, Blache D, Martin GB, D'Occhio MJ. 2013. Interrelationships of nutrition, metabolic hormones and resumption of ovulation in multiparous suckled beef cows on subtropical pastures. Anim Reprod Sci, 137:137-144.

Santos APC, Orlandi RE, Bottino MP, Simões LMS, Lima EA, Silva AG, Guerreiro BM, Bastos MR, Freitas BG, Bertoncini FLS, Santos JA, Sales JNS. 2018. Effect of pre-exposition to injectable long acting progesterone on pregnancy rates of suckled beef cows submitted to the estrous synchronization protocol. Anim Reprod, 15:328. (Abstract).

Schillo KK. 1992. Effects of dietary energy on control of luteinizing hormone secretion in cattle and sheep. $J$ Anim Sci, 70:1271-1282.

Silva L, Simoes LMS, Bottino MP, Santos APC, Santos G, Martinez IYH, Souza JC, Baruselli PS, Sales JNS. 2018. Presynchronization by induction of a largest follicle using a progesterone device in GnRHbased-ovulation synchronization protocol in crossbred dairy cows. Theriogenology, 119:233-237.

Simões LMS, Orlandi RE, Massoneto JPM, Scandiuzzi LA, Jr, Freitas BG, Bastos MR, Souza JC, Sales JNS. 2018. Exposure to progesterone previous to the protocol of ovulation synchronization increases the follicular diameter and the fertility of suckled Bos indicus cows. Theriogenology, 116:28-33.

Souza AH, Ayres H, Ferreira RM, Wiltbank MC. 2008. A new presynchronization system (DoubleOvsynch) increases fertility at first postpartum timed AI in lactating dairy cows. Theriogenology, 70:208-215.

Vasconcelos JL, Silcox RW, Rosa GJ, Pursley JR, Wiltbank MC. 1999. Synchronization rate, size of the ovulatory follicle, and pregnancy rate after synchronization of ovulation beginning on different days of the estrous cycle in lactating dairy cows. Theriogenology, 52:1067-1078.

Williams GL, Gazal OS, Vega GAG, Stanko RL. 1996. Mechanisms regulating suckling-mediated anovulation in the cow. Anim Reprod Sci, 42:289-297.

Wiltbank MC, Baez GM, Cochrane F, Barletta RV, Trayford CR, Joseph RT. 2015. Effect of a second treatment with prostaglandin F2alpha during the Ovsynch protocol on luteolysis and pregnancy in dairy cows. J Dairy Sci, 98:8644-8654.

Yavas Y, Walton JS. 2000. Postpartum acyclicity in suckled beef cows: a review. Theriogenology, 54:25-55. 